\title{
O monitoramento ambiental realizado pela Secretaria Municipal de Meio Ambiente e Secretaria Municipal de Saúde: estudo de caso em Volta Redonda/RJ
}

\author{
The environmental monitoring carried out by the Municipal \\ Department of Environment and Municipal Health Department: case \\ study in Volta Redonda/RJ
}

1 Francisco Jácome Gurgel Júnior gurgel.jr@gmail.com Doutor em Ciências Ambientais e Florestais, Professor do curso de Engenharia Ambiental e Engenharia Civil do UniFOA e da
Secretaria Estadual de Educação do Rio de Janeiro/SEEDUC. Centro Universitário de Volta Redonda- UniFOA.

\section{RESUMO}

Os recursos ambientais descritos pela lei federal $n^{\circ}$ 6.938/81, que dispõe sobre a Política Nacional de Meio Ambiente são protegidos por várias normas legais previstas no arcabouço da legislação ambiental brasileira e o monitoramento ambiental se constitui em instrumento fundamental para o controle pelos órgãos ambientais integrantes do Sistema Nacional de Meio Ambiente (SISNAMA). Com o apoio dessa importante ferramenta, a Gestão Ambiental torna-se mais eficaz e abrangente, pois permite aos gestores públicos e privados o acompanhamento constante da qualidade ambiental do meio ambiente com o apoio de técnicas e equipamentos que permitem a adoção de medidas tempestivas para se evitar a degradação ambiental. Neste estudo, o enfoque foi no sistema de monitoramento ambiental existente no município de Volta Redonda, instrumentalizado pela Secretaria Municipal de Meio Ambiente (SMMA) e pela Secretaria Municipal de Saúde (SMS), identificando os mecanismos adotados, a metodologia utilizada, os recursos ambientais monitorados, a periodicidade, custos de implantação, meios de divulgação à sociedade e demais informações acerca dessa relevante ferramenta de proteção ao meio ambiente.

\section{Palavras-chave:}

Monitoramento. Meio ambiente. Recursos ambientais. Volta Redonda/RJ.

\begin{abstract}
The environmental resources described by Federal Law No. 6.938 / 81, which provides the National Environmental Policy, are protected by several legal norms foreseen in the framework of Brazilian environmental legislation and environmental monitoring and constitutes a fundamental instrument for the control of these by the environmental agencies members of the National Environmental System (SISNAMA). With the support of this important tool, Environmental Management becomes more effective and comprehensive, as it allows public and private managers to constantly monitor the environmental quality with the support of techniques and equipment that allow the adoption of timely measures to avoid environmental degradation. In this study, the focus was on the environmental monitoring system in the municipality of Volta Redonda and instrumented by the Municipal Environment Secretariat (SMMA) and the Municipal Health Department (SMS), identifying the mechanisms adopted, the methodology used, the monitored environmental resources, the periodicity, the implementation costs, the means of dissemination to society and other information about this relevant tool to protect the environment.
\end{abstract}

\section{Keywords:}

Monitoring. Environment. Environmental resources. Volta Redonda / RJ.

\section{Como você deve citar?}

GURGEL JÚNIOR, Francisco Jácome. O monitoramento ambiental realizado pela Secretaria Municipal de Meio Ambiente e Secretaria Municipal de Saúde: estudo de caso em Volta Redonda/RJ. Cadernos UniFOA, Volta Redonda, n. 45, p. 45-55, abril 2021. 
O monitoramento ambiental realizado pela Secretaria Municipal de Meio Ambiente e Secretaria Municipal de Saúde: estudo de caso em Volta Redonda/RJ

\section{INTRODUÇÃO}

O objeto deste estudo é a cidade de Volta Redonda, localizada na região denominada Sul Fluminense e situada no vale do Médio Paraíba, entre a Serra do Mar e a Serra da Mantiqueira, com população estimada de 263.659 habitantes (IBGE, 2020), sede da maior usina siderúrgica da América Latina, terceira maior receita fiscal do estado e que abriga 4.829 empresas atuantes (PMVR, 2016).

É imprescindível para os citadinos a atuação responsável dos órgãos públicos locais, no sentido de proteger e gerir os recursos naturais existentes e que são vitais para a boa qualidade de vida dos munícipes, monitorando e fiscalizando o ar, as águas, os resíduos, o solo, o subsolo e as áreas verdes localizadas na jurisdição municipal.

Nesta pesquisa, discutem-se as atividades rotineiras de monitoramento ambiental efetivamente realizadas pela Secretaria Municipal de Meio Ambiente (SMMA) e pela Secretaria Municipal de Saúde (SMS) de Volta Redonda, nos limites do município. Serão também destacados os recursos ambientais monitorados, os equipamentos utilizados para tal fim, sua frequência e resultados apresentados, as medidas tomadas para a preservação e controle, bem como as formas de divulgação adotadas pelos órgãos consultados.

A lei $n^{\circ} 4.438 / 08$, que dispõe sobre a criação do Código Municipal de Meio Ambiente de Volta Redonda, em seu artigo $4^{\circ}$, inciso $\mathrm{VII}$, cita o monitoramento ambiental como um dos instrumentos previstos na Política municipal de Meio Ambiente e se configura em importante ferramenta de gestão ambiental para os gestores locais. A lei federal $n^{\circ} 6.938 / 81$ (BRASIL, 1981), que dispõe sobre a Política Nacional de Meio Ambiente, é outro dispositivo legal que elenca em seu artigo $2^{\circ}$, inciso VII, o acompanhamento do estado da qualidade ambiental como um dos princípios balizadores da respectiva norma legal.

\section{REVISÃO BIBLIOGRÁFICA}

Tanto no planejamento quanto no cotidiano da gestão ambiental, um vocábulo é usado com constância, embora nem sempre o seu significado seja bem esclarecido. Trata-se da palavra "monitoramento". Em geral, o monitoramento é revestido de explicações sofisticadas e complexas, tratado com muita cerimônia e todos enfatizam a sua importância, embora poucos reconheçam que o praticam constantemente.

O Instituto Nacional de Pesquisas da Amazônia (2013) endossa que o monitoramento ambiental integrado é de fundamental importância para os tomadores de decisões políticas, pois os resultados podem orientar a adoção de medidas preventivas e corretivas. Em outras palavras, monitorar é estudar e acompanhar - contínua e sistematicamente - o comportamento de fenômenos, eventos e situações específicas, cujas condições desejamos identificar, avaliar e comparar. Dessa forma, é possível estudar as tendências ao longo do tempo, ou seja, verificar as condições presentes, projetando as situações futuras (BRASIL, 2006).

Bitar e Braga (2012) endossam que os gestores municipais e organizações da sociedade requerem cada vez mais informações consistentes e objetivas acerca da situação ambiental em seu território. 0 monitoramento ambiental serve para se conhecer o estado e as tendências qualitativas e quantitativas dos recursos naturais e as influências exercidas pelas atividades humanas e por fatores naturais sobre o meio ambiente (BRASIL, 2006). Tal conhecimento permite estabelecer critérios para a tomada de decisões emergenciais, com o objetivo de se evitar situações críticas, como enchentes, deslizamentos de terra, "apagões", bem como para minimizar os seus efeitos.

O Instituto Brasileiro de Geografia e Estatística (IBGE, 2004) define monitoramento ambiental como o "acompanhamento periódico através de observações sistemáticas de um atributo ambiental, 
de um problema ou situação através da quantificação das variáveis que o caracterizam". Ainda segundo o Instituto Brasileiro de Geografia e Estatística (IBGE, 2004), o monitoramento ambiental determina os desvios entre normas preestabelecidas (referenciais) e as variáveis medidas.

São Paulo (2009) conceitua a avaliação de risco como o processo pelo qual são identificados, avaliados e quantificados os riscos à saúde humana, ao meio ambiente e a outros bens a proteger.

O World Bank (1978 apud FEEMA, 1990) esclarece que o monitoramento ambiental é a determinação contínua e periódica da quantidade de poluentes ou de contaminação radioativa presente no meio ambiente. Botking e Keller (2011) entendem que o monitoramento ambiental é o processo de coleta de informação regular em locais específicos para se obter uma base de dados da qual se pode avaliar e citam como exemplo a coleta de amostras de água debaixo de um aterro para alertar antecipadamente, caso haja algum problema de poluição.

O monitoramento ambiental é de fundamental importância para as organizações e órgãos públicos no sentido de antever o risco de acidentes e/ou contaminação que possam redundar em danos nos recursos ambientais e, assim, adotar tempestivamente medidas preventivas e eficazes no sentido de minimizar catástrofes. A implantação de atividades de monitoramento ambiental necessita de uma seleção prévia de indicadores, que são padrões que expressam as condições qualitativas e/ou quantitativas do que está sendo medido e avaliado.

A escolha dos indicadores depende dos objetivos do monitoramento, do que se quer monitorar e das informações a obter. Segundo o Ministério do Meio Ambiente (BRASIL, 2006), os indicadores devem descrever, de forma compreensível e significativa: o estado e as tendências dos recursos ambientais, a situação socioeconômica da área em estudo e o desempenho de instituições no cumprimento das suas atribuições.

O Ministério do Meio Ambiente (BRASIL, 2006) relaciona os seguintes indicadores locais de sustentabilidade: consumo de água, consumo de energia, produção de resíduo, qualidade do ar, qualidade da água, espécies indicadoras, eficiência no uso do solo, desemprego, nível de ruído, reciclagem (volume e facilidades), compostagem doméstica, energia renovável, padrões de viagens, acesso ao ambiente natural, acidentes (riscos), crimes (riscos) e existência da Agenda 21 (gestão, correção futura, planejamento e projetos).

\section{MATERIAL E MÉTODOS}

Para a obtenção de dados necessários à análise pormenorizada do status do monitoramento ambiental no município de Volta Redonda, foram expedidos dois ofícios, sendo um para a Secretaria Municipal de Meio Ambiente e outro remetido à Secretaria Municipal de Saúde, solicitando informações indispensáveis que possam demonstrar de maneira fática a atuação desses dois órgãos públicos na área acima descrita.

Nesse ofício, foi solicitada a metodologia adotada para coleta dos dados, os equipamentos utilizados, os recursos humanos atuantes nessa seara, a periodicidade da coleta de dados, os locais escolhidos, os recursos monitorados e demais informações inerentes a esse instrumento de controle ambiental. Com a obtenção, análise e tabulação dos dados solicitados junto às duas secretarias municipais, foi possível traçar o estado do monitoramento ambiental no município de Volta Redonda, com base nos parâmetros legais definidos pela Resolução CONAMA n 03/90 (BRASIL, 1990), Lei Federal n 6.938/81 - Política Nacional de Meio Ambiente (BRASIL, 1981), e Portaria n².914/11 do Ministério da Saúde (BRASIL, 2011). 
O monitoramento ambiental realizado pela Secretaria Municipal de Meio Ambiente e Secretaria Municipal de Saúde: estudo de caso em Volta Redonda/RJ

Nesta pesquisa, também se pretende a identificação das potencialidades, fragilidades e apontamento de oportunidades de melhoria na execução dessa atividade de controle ambiental. Monitorar a qualidade do ar é extremamente importante, pois através dele se verifica o nível de concentração dos poluentes presentes na atmosfera (dióxido de enxofre- $\mathrm{SO}_{2}$, partículas totais em suspensão (PTS), partículas inaláveis (PM10), monóxido de carbono (CO), oxidantes fotoquímicos expressos como ozônio- $\mathrm{O}_{3^{\prime}}$, hidrocarbonetos totais $(\mathrm{HC})$ e dióxido de nitrogênio $\left(\mathrm{NO}_{2}\right)$ e seus resultados permitem um acompanhamento sistemático do ar e permitem, através da área monitorada, a elaboração de diagnósticos da qualidade do ar, subsidiando ações governamentais para o controle das emissões.

Entende-se como poluente atmosférico qualquer forma de matéria ou energia com intensidade e quantidade, concentração, tempo ou características em desacordo com os níveis estabelecidos, e que tornem ou possam tornar o ar: impróprio, nocivo ou ofensivo à saúde; inconveniente ao bem-estar público; danoso aos materiais, à fauna e flora; prejudicial à segurança, ao uso e gozo da propriedade e as atividades normais da comunidade, conforme disposto na Resolução CONAMA nº 03/90 (BRASIL, 1990).

\subsection{A atuação da Secretaria Municipal de Meio Ambiente (SMMA) no Monitoramento Ambiental}

Segundo informações fornecidas pelo Departamento de Controle Ambiental (DCA) da SMMA/ VR, em resposta ao Ofício nº 001/2017 (VOLTA REDONDA, 2017), o setor conta atualmente com seis agentes fiscais que são responsáveis por concretizar a fiscalização ambiental através do poder de polícia inerente a sua função, que se consubstancia pela lavratura de auto de infração e instauração de processos administrativos no âmbito de suas atribuições.

Conforme as informações do Diretor do referido departamento, a fiscalização foca nos seguintes parâmetros: verificação da existência de licença ambiental, acompanhamento de atividade licenciada, validade da licença, a operação dos sistemas de controle por parte dos empreendedores licenciados, atendimento às restrições contidas nas licenças e observação dos pontos de geração de poluição e seus respectivos sistemas de controle. No que tange à poluição atmosférica, o DCA atesta que faz a observação dos pontos de emissão e emanações fortuitas, considerando odor, coloração e presença de material particulado, bem como verifica a presença e eficiência das medidas de controle.

Quanto à poluição por efluentes líquidos, o DCA afirma que verifica os pontos de lançamento de efluentes líquidos, de esgotos sanitários, efluentes industriais ou águas contaminadas, avaliando seus pontos de geração e a existência e eficiência do sistema de tratamento de efluentes líquidos, assim como a destinação dos efluentes líquidos (rede pública ou corpo hídrico).

$\mathrm{Na}$ área de poluição por resíduos sólidos, se analisa a sua geração, formas de acondicionamento, reaproveitamento, reciclagem, tratamento e disposição final dos rejeitos e também a verificação da documentação que comprova a destinação dos resíduos, em caso de encaminhamento a terceiros. A poluição sonora é avaliada se a atividade licenciada causar incômodos à vizinhança. A SMMA, segundo a resposta ao ofício, dispõe de uma central de atendimento a denúncias que se encarrega de centralizar o recebimento, sistematização e acompanhamento de queixas da sociedade, relativas a danos ou agressões ambientais.

\subsection{A atuação da Secretaria Municipal de Saúde (SMS) no Monitoramento Ambiental}

A SMS de Volta Redonda instituiu, a partir de dois mil e doze, a Vigilância Ambiental (VIGAM), por força da Lei Municipal n 4.800/2011, que cria o setor e regulamenta sua atuação. A VIGAM desenvolve, na área de controle de poluição, um projeto de Vigilância do ar através do VIGIAR, no qual há o ma- 
peamento e o cadastramento das principais áreas de risco da poluição do ar, em particular das áreas urbanas, identificando a existência e necessidade do sistema de monitoramento da qualidade do ar.

Segundo o setor pesquisado, o monitoramento deve dar prioridade a substâncias químicas e a agentes físicos de comprovado efeito maléfico a saúde humana. O VIGIAR é responsável pela coordenação do sistema de informação de vigilância e controle da qualidade do ar e pela identificação, acompanhamento e avaliação das ações e as metas das pactuações correspondentes a sua competência. O VIGIAR, anualmente, cumpre a meta pactuada com a Secretaria Estadual de Saúde (SES), onde o Instrumento de Identificação dos Municípios de Risco (IIMR) é preenchido e também um relatório de detalhamento de potenciais fontes de risco para a Vigilância Ambiental em saúde relacionada à qualidade do ar, em que uma fonte fixa é caracterizada.

Segundo a SMS/VR, a implantação de Unidades Sentinelas em localidades consideradas prioritárias é uma das estratégias de atuação do VIGIAR. Em março de 2012, iniciou-se o desenvolvimento do "Projeto para Implantação das Unidades Sentinelas de Vigilância em Saúde relacionada à Qualidade do Ar", em dois bairros selecionados: Distrito Norte - UBSF Siderlândia e Distrito Sul - UBSF Conforto. 0 primeiro devido à localização, entorno da CSN, da Fábrica de Cimentos Tupi, da fábrica de Cal da CSN e devido estar localizado na Avenida Almirante Adalberto de Barros Nunes, popularmente conhecida como Avenida Beira Rio. A unidade possui três equipes de saúde da família, estrutura física, recursos humanos e materiais suficientes para o desenvolvimento de suas atividades, conforme a resposta da SMS/VR.

O VIGIAR, através das sentinelas, executa triagem na recepção das unidades de saúde, identificando crianças menores de cinco anos e indivíduos com idade a partir de sessenta anos que apresentem: um ou mais sintomas respiratórios descritos como dispneia, falta de ar, cansaço, sibilos, chiados no peito, tosse associada a outro sintoma respiratório, asma e bronquite. Para o atendimento dos indivíduos que se enquadre nos critérios anteriormente citados, a recepção deverá anexar ao prontuário dos pacientes a "Ficha de Coleta de Dados da Unidade Sentinela de Vigilância da Qualidade do Ar".

O VIGIAR ainda informa que orienta os agentes comunitários da SMS/VR a alertar a população das áreas monitoradas para procurarem a unidade mais próxima de suas residências, quando apresentarem problemas respiratórios. Após a triagem, realiza-se o preenchimento das informações clínicas pelos profissionais responsáveis pelo atendimento que, posteriormente, são enviadas ao Centro de Controle de Zoonoses (CCZ), que se encarrega de remeter os dados ao Sistema Único de Saúde (SUS).

Os dados gerados são analisados pela unidade de análise composta pela equipe do programa VIGIAR e membros da vigilância epidemiológica municipal, visando ao planejamento de ações de saúde. $\mathrm{Na}$ área de controle e vigilância da água para consumo humano, desenvolve-se o VIGIÁGUA, no qual, semanalmente, realiza-se coleta de amostras de água em pontos estrategicamente selecionados em sistemas de abastecimento de água para consumo humano e em soluções alternativas coletivas de abastecimento de água, de acordo com a Portaria Federal n 2.914/11, do Ministério da Saúde (BRASIL, 2011), que dispõe sobre os procedimentos de controle e de vigilância da qualidade da água para consumo humano e seu padrão de potabilidade.

De acordo com as informações do VIGIÁGUA, são coletadas, em média, 10 amostras semanais, conforme determina o Capítulo VI (dos Planos de Amostragem), da Portaria Federal $n^{\circ}$ 2.914/11 (BRASIL, 2011), totalizando 40 amostras mensais, em média, que são encaminhadas para o LACEN, que é o laboratório de referência indicado para as análises complementares. Ainda segundo o VIGIÁGUA, concomitantemente, acontece a coleta de amostras para a realização das análises pela própria companhia de abastecimento do município (Serviço Autônomo de Água e Esgoto-SAAE), para posterior avaliação de ambos os laudos mensais em conjunto. 
O monitoramento ambiental realizado pela Secretaria Municipal de Meio Ambiente e Secretaria Municipal de Saúde: estudo de caso em Volta Redonda/RJ

O VIGISOLO tem por objetivo desenvolver ações de vigilância em saúde de populações expostas a solo contaminado, visando ao conhecimento, à detecção ou à prevenção de quaisquer mudanças nos fatores determinantes e condicionantes do meio ambiente que interferem na saúde humana, com a finalidade de recomendar e adotar medidas de promoção da saúde ambiental, prevenção e controle dos fatores de risco relacionados às doenças e outros agravos à saúde.

De acordo com a Divisão de Vigilância Ambiental, o VIGISOLO implementará ações estratégicas que visam: identificação de populações expostas ou sob risco de exposição a contaminantes presentes no solo; elaboração de diretrizes para o acompanhamento da saúde de populações expostas ou sob risco de exposição a contaminantes presentes no solo; articulação intrasetorial para a implementação das diretrizes que visam ao acompanhamento da saúde de populações expostas ou sob risco de exposição a contaminantes presentes no solo; levantamento e cadastramento sistemático de áreas com populações expostas ou sob risco de exposição a solo contaminado, de forma conjunta com os órgãos ambientais e outros órgãos afins; classificação e priorização de áreas com populações expostas ou sob risco de exposição a solo contaminado; elaboração de instrumento de avaliação de risco à saúde humana e definição de estratégias para a inserção do instrumento de avaliação de risco à saúde humana.

No município de Volta Redonda, anualmente, é feita a identificação de área com população exposta a solo contaminado e produção de um relatório de acompanhamento anual das ações do VIGISOLO nos municípios e estados, que é enviado à Secretaria Estadual de Saúde do estado do Rio de Janeiro. Na resposta ao ofício enviado à SMS, só consta o acompanhamento da área denominada Condomínio Volta Grande IV, que se iniciou em 06/08/2012 e onde foram identificados contaminantes de resíduos industriais, resíduos químicos e metais pesados, todos provenientes do beneficiamento do aço, produzido pela Companhia Siderúrgica Nacional (CSN).

Nessa mesma área, o questionário aplicado pelo VIGISOLO identificou um total de 827 imóveis, sendo que 20 destes encontravam-se sem moradores no período do estudo; são 12 imóveis onde os ocupantes se recusaram a responder o questionário e; em 14, os moradores não foram encontrados. Identificou-se que $96,5 \%$ dos imóveis são residenciais e que $100 \%$ da população estudada consome água fornecida pelo Serviço Autônomo de Água e Esgoto de Volta Redonda.

Em, aproximadamente, $20 \%$ das residências a área externa não possui impermeabilização. 0 VIGISOLO aplicou 781 questionários que totalizaram 2.073 moradores. Atualmente essa área é monitorada pelo Núcleo de Vigilância em Saúde localizado na Unidade Básica de Saúde da Família (UBSF) Volta Grande, composto pela Vigilância Ambiental, Núcleo de Apoio à Saúde da Família (NASF), Epidemiologia, Saúde do Trabalhador e Atenção Básica.

\section{RESULTADOS E DISCUSSÕES}

A análise dos dados enviados pelas Secretarias Municipais de Saúde e Meio Ambiente do município de Volta Redonda permite concluir que só se monitora regularmente a poluição atmosférica e, mesmo assim, se faz com equipamentos do órgão ambiental seccional (Instituto Estadual do Ambiente/ INEA) e da Companhia Siderúrgica Nacional (CSN), pois o município não dispõe de recursos humanos e materiais para efetivar tal controle de maneira autônoma.

Rocha e Guimarães (2017) atestam, em sua pesquisa, que os valores das Partículas Totais em Suspensão (PTS), do Material Particulado Inalável (MP10) e Ozônio $\left(\mathrm{O}_{3}\right)$ ultrapassaram os limites da legislação brasileira, no período de 2010 a 2014, no município. O VIGIAR da SMS/VR também exerce certo controle dos pacientes acometidos por doenças respiratórias que são atendidos pela rede pública de saúde, 
mas não apontou de maneira concreta as ações de caráter preventivo e corretivo que são tomadas para se estabelecer se existe nexo causal entre a poluição atmosférica que atinge os volta-redondenses com as condições locais ou se as doenças respiratórias são hereditárias ou ligadas ao histórico do paciente.

De maneira geral, os efeitos dos gases poluentes na saúde humana estão intimamente associados a sua solubilidade nas paredes do aparelho respiratório, fato este que determina a quantidade do poluente capaz de atingir as regiões mais distais dos pulmões. Há evidências de que o dióxido de enxofre agrava as doenças respiratórias pré-existentes e contribui para seu aparecimento. 0 dióxido de nitrogênio, devido a sua baixa solubilidade, é capaz de penetrar profundamente no sistema respiratório, podendo dar origem às nitrosaminas, algumas das quais podem ser carcinogênicas. Também é um poderoso irritante, podendo causar sintomas que lembram aqueles do enfisema.

A presença de oxidantes fotoquímicos na atmosfera tem sido associada à redução da capacidade pulmonar e ao agravamento das doenças respiratórias, como a asma (RIO DE JANEIRO, 2016)

Os efeitos da exposição ao monóxido de carbono estão associados à diminuição da capacidade de transporte de oxigênio pelo sangue. Foi demonstrado, experimentalmente, que a pessoa exposta ao monóxido de carbono pode ter diminuídos seus reflexos e acuidade visual e sua capacidade de estimar intervalos de tempo.

Altos índices do poluente em áreas de fluxo intenso de veículos têm sido apontados como causa adicional de acidentes de trânsito. Poeiras em suspensão no ar afetam a capacidade de o sistema respiratório remover as partículas do ar inalado, retendo-as nos pulmões; quanto mais finas as partículas, mais profundamente penetram no aparelho respiratório.

As poeiras em suspensão também potencializam os efeitos dos gases presentes no ar. A região do Médio Paraíba compreende os municípios de Resende, Barra Mansa, Volta Redonda, Barra do Piraí, Rio Claro, Piraí, Valença, Rio das Flores, Itatiaia, Quatis e Porto Real e, segundo o Instituto Estadual do Ambiente (BRASIL, 2011), o monitoramento da qualidade do ar nessa região é realizado por meio de três estações automáticas de propriedade da Companhia Siderúrgica Nacional (CSN), além da rede manual composta por nove estações de amostragem de material particulado: três da rede INEA e as demais operadas pela CSN.

A população consegue acessar os dados provenientes das estações acima citadas pelo site da Prefeitura Municipal de Volta Redonda, pelo link http://www.portalvr.com/meioambiente/iqa.php ou pelo site do INEA, acessando o link http://www.inea.rj.gov.br/fma/qualidade-ar-rapido.asp?cat=65.

Em Volta Redonda, os volta-redondenses têm ainda à disposição um painel eletrônico que fica situado no bairro Vila Santa Cecília e que informa a situação da qualidade do ar em diversos pontos da cidade, conforme apresentado na figura 1. 
O monitoramento ambiental realizado pela Secretaria Municipal de Meio Ambiente e Secretaria Municipal de Saúde: estudo de caso em Volta Redonda/RJ

Figura 1 - Vista do painel informativo da qualidade do ar em Volta Redonda localizado no bairro Vila Santa Cecília

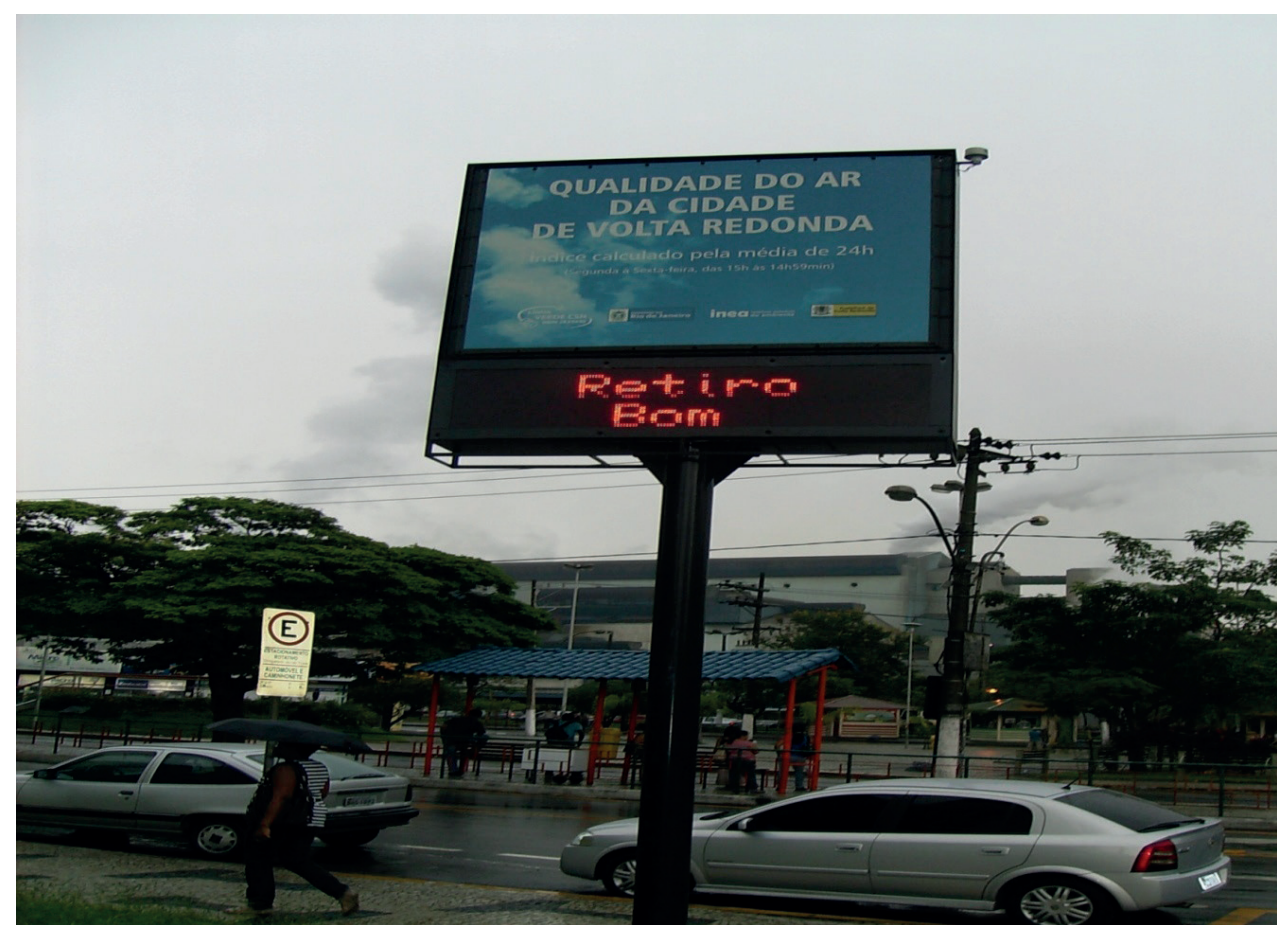

Fonte: Gurgel Júnior (2012)

A SMMA/VR não realiza efetivamente o monitoramento de nenhum dos recursos ambientais descritos na lei federal no 6.938 (BRASIL, 1981), que dispõe sobre a Política Nacional de Meio Ambiente e que cita a atmosfera, as águas interiores, superficiais e subterrâneas, os estuários, o mar territorial, 0 solo, o subsolo, os elementos da biosfera, a fauna e a flora como objeto da gestão ambiental pública. Ferreira (2013) advoga que é imprescindível a existência de planejamento urbano e rural, onde o uso e ocupação do solo devem ser feitos de maneira adequada, como auxílio da população do município.

Como aponta a FEEMA (1991), a qualidade do ar em Volta Redonda encontra-se, desde aquela época, bastante comprometida e a situação perdura até hoje em função dos altos índices de partículas totais em suspensão (PTS), partículas inaláveis, dióxido de enxofre $\left(\mathrm{SO}_{2}\right)$, dióxido de nitrogênio $\left(\mathrm{NO}_{2}\right)$, monóxido de carbono (CO) e ozônio $\left(\mathrm{O}_{3}\right)$.

A topografia e as condições meteorológicas predominantes desaconselhariam, do ponto de vista ambiental, a instalação de indústrias na região, sobretudo uma indústria de grande porte como a CSN, tendo em vista que os ventos predominantes de leste para oeste provocam uma poluição exacerbada nos bairros localizados à margem esquerda do rio Paraíba do Sul ou grande Retiro, principalmente pelas chaminés dos três altos-fornos da CSN.

As secretarias municipais pesquisadas não responderam à maioria dos questionamentos exarados nos ofícios enviados e percebeu-se a ausência de informações relevantes acerca do monitoramento ambiental, como, por exemplo: as parcerias adotadas pelos órgãos para a potencialização do monitoramento em nível municipal; os dispositivos legais vigentes que balizam essa atividade; os indicadores ambientais adotados para nortear os trabalhos; a frequência e os métodos de análises estatísticas utilizados; os custos estimados para a municipalidade executar tal função; o sistema de divulgação dos resultados alcançados para a sociedade; as propostas para remediação das áreas 
contaminadas e as dificuldades encontradas pelos órgãos para a implementação do monitoramento ambiental em nível local.

Outra ausência sentida nas respostas aos ofícios enviados é a omissão quanto aos equipamentos utilizados pela Divisão de Vigilância Ambiental (SMS) e pelo Departamento de Controle Ambiental (SMMA) no exercício do monitoramento ambiental praticado por ambos. Oliveira et al. (2008) destacam em seu estudo que pesquisas sobre monitoramento ambiental e fontes de informação têm sido cada vez mais frequentes na literatura e que o ambiente externo ainda tem despertado especial atenção para muitos pesquisadores de diversos campos da ciência, especialmente para aqueles ligados às ciências administrativas, organizacionais, informacionais e biológicas.

\section{RECOMENDAÇõES}

A Prefeitura Municipal de Volta Redonda deveria constituir um Grupo de Trabalho intersecretarial, de modo a integrar as ações de monitoramento ambiental realizadas pelas Secretarias Municipais de Meio Ambiente e de Saúde, visando à potencialização de medidas de cunho fiscalizatório, preventivo e corretivo na área de monitoramento ambiental, conjugação de esforços e troca de experiências entre os setores.

A parceria com órgãos estaduais e federais também seria desejável para estreitar laços e obter novos conhecimentos e práticas desenvolvidas por outras esferas de governo, conforme reza no artigo 23, IV da Lei Municipal n 4.800 (VOLTA REDONDA, 2011), que estabelece como competência da Divisão de Vigilância Ambiental a promoção, junto aos órgãos afins, de ações de proteção da saúde humana relacionadas ao controle e à recuperação do meio ambiente. Seria interessante também a divulgação dos trabalhos já desenvolvidos nessa área pelas duas secretarias e a realização de eventos (seminários, congressos, audiências públicas, etc.).

Seria desejável também a apresentação das políticas públicas efetivadas nessa seara, bem como a instituição de canais de comunicação com esses entes, a fim de facilitar a denúncia por parte da população volta-redondense de possíveis agressões aos recursos ambientais, objeto desta pesquisa. As secretarias pesquisadas deveriam se posicionar publicamente acerca das outras áreas contaminadas existentes em Volta Redonda que se encontram listadas no cadastro de áreas contaminadas e reabilitadas do estado do Rio de Janeiro, produzido pelo Instituto Estadual do Ambiente (INEA) que, em sua $3^{\mathrm{a}}$ edição, menciona oito áreas contaminadas no município, além do Volta Grande IV, que é citado pelo VIGISOLO em seu relatório.

A pesquisa também aponta para a falta de parcerias com universidades, empresas, organizações do terceiro setor, Ministério Público, órgãos de classe e demais instituições que poderiam auxiliar o Poder Público com recursos de ordem material e humana na ampliação da rede de monitoramento ambiental já consolidada.

A existência de passivos ambientais na jurisdição do município de Volta Redonda é um assunto de grande relevância pública e, dessa forma, o Poder Público local deve se posicionar concretamente acerca da atual situação dessas áreas e do monitoramento ambiental efetuado, de forma a se engajar para tomada imediata de medidas cabíveis pela municipalidade e/ou órgãos afıns para a devida remediação das situações apresentadas. Convém, portanto, que as informações reunidas no município sejam sistematizadas em um Relatório Local do Estado do Meio Ambiente, que será a base do monitoramento ambiental e permitirá que se obtenha um panorama real capaz de fornecer mais informações que apenas grupos de dados isolados. Desenvolver um sistema de monitoramento ambiental complexo e eficiente será importante para balizar a atuação dos órgãos ambientais municipais e resultará em benefícios econômicos, ambientais e sociais imensuráveis e que contribuirão para uma Volta Redonda mais sustentável. 
O monitoramento ambiental realizado pela Secretaria Municipal de Meio Ambiente e Secretaria Municipal de Saúde: estudo de caso em Volta Redonda/RJ

\section{REFERÊNCIAS}

BITAR, O. Y. \& BRAGA, T. O. Indicadores ambientais aplicados a gestão municipal. In: PHILIPPI JR, A \& MALHEIROS, F. T. (Orgs.). Indicadores de sustentabilidade e gestão ambiental. São Paulo. Editora Manole, 2012.

BOTKIN, D. B. \& KELLER, E. A. Ciência Ambiental: terra, um planeta vivo. 7. ed. Rio de Janeiro. Editora LTC. 2011. 681p.

BRASIL. Lei Federal n 6.938/81. Política Nacional do Meio Ambiente. 1981. Brasília. Distrito Federal.

BRASIL. Resolução CONAMA n 03/90. Dispõe sobre padrões de qualidade do ar, previstos no PRONAR. Publicada no DOU, de 22 de agosto de 1990, Seção 1, páginas 15937-15939.

BRASIL. Ministério do Meio Ambiente. Cadernos de formação volume 4: instrumentos de gestão ambiental municipal. Brasília/DF. 74p. 2006.

BRASIL. Portaria Ministerial $n^{\circ}$ 2.914/11. Dispõe sobre os procedimentos de controle e de vigilância da qualidade da água para consumo humano e seu padrão de potabilidade. Ministério da Saúde. Distrito Federal/DF.

FUNDAÇÃO ESTADUAL DE ENGENHARIA DO MEIO AMBIENTE (Rio de Janeiro). Vocabulário básico de meio ambiente. Rio de Janeiro, 1990.

FundaÇÃo estadual de engenharia do MEIO AMBiente (Rio de Janeiro).. Perfil do Município de Volta Redonda. Rio de Janeiro, 98p. 1991.

FERREIRA, E. Geoprocessamento aplicado ao monitoramento ambiental, texto: análise quantitativa de parâmetros biofísicos de bacia hidrográfica obtidos por sensoriamento remoto. (D.O.I.: 10.5216/ reec.v7i1.25193). REEC - Revista Eletrônica de Engenharia Civil, 7(1). https://doi.org/10.5216/reec. v7i1.25193, 2013.

GURGEL JÚNIOR, F. J. Gestão ambiental municipal: estudo de caso de Volta Redonda/RJ, no período 2005-2012. 149p. Tese (Doutorado) - Universidade Federal Rural do Rio de Janeiro, Seropédica, 2012.

INSTITUTO BRASILEIRO DE GEOGRAFIA E ESTATÍSTICA (Brasil). Vocabulário Básico de Recursos Naturais e Meio Ambiente. 2. ed. Rio de Janeiro. 2004. 332p.

INSTITUTO BRASILEIRO DE GEOGRAFIA E ESTATÍSTICA (Brasil). Cidades. Disponível em: https://cidades. ibge.gov.br/brasil/rj/volta-redonda/panorama. Acesso em: 17 dez. 2020.

INSTITUTO ESTADUAL DO AMBIENTE (Rio de Janeiro). Disponível em: http://www.inea.rj.gov.br/. Acesso em: 07 dez. 2017.

INSTITUTO NACIONAL DE PESQUISAS DA AMAZÔNIA/INPA. Biodiversidade e monitoramento ambiental integrado (livro eletrônico). Santo André/SP. Áttema Editorial. $9.572 \mathrm{~Kb}, 2013$. Disponível em: https:// ppbio.inpa.gov.br/sites/default/files/ Biodiversidade_e_monitoramento_ambiental_integrado.pdf. Acesso em: 07 dez. 2020.

OLIVEIRA, P. H.; NETO, W. P. \& OLIVEIRA, F. R. Monitoramento ambiental e fontes de informação para a tomada de decisão estratégica: o caso dos varejos formais instalados nas imediações do shopping popular Oiapoque em Belo Horizonte. Ci. Inf., Brasília, v. 37, n. 3, p. 103-114, set./dez. 2008. 
PREFEITURA MUNICIPAL DE VOLTA REDONDA (Brasil). Disponível em: http://www.portalvr.com.br/. Acesso em: 02 jul. 2016.

RIO DE JANEIRO. Resolução CONEMA n 70/16. Estabelece os limites de emissão veicular a serem aplicados nos programas de controle da poluição veicular implantados no Estado do Rio de Janeiro, e dá outras providências. Publicado no DOE - RJ em 28 janeiro 2016.

ROCHA, N. L. T. E.; GUIMARÃES, C. S. Estudo da qualidade do ar e a atividade siderúrgica na cidade de Volta Redonda. Cadernos UniFOA. n. 33, p. 25-36. Abr. 2017.

SÃO PAULO. Lei Estadual $n^{\circ}$ 13.377/09. Dispõe sobre diretrizes e procedimentos para a proteção da qualidade do solo e gerenciamento de áreas contaminadas, e dá outras providências correlatas. 2009. São Paulo/SP.

VOLTA REDONDA. Lei Municipal $\mathbf{n}^{\circ} \mathbf{4 . 4 3 8 / 0 8}$. Dispõe sobre a criação do Código Municipal de Meio Ambiente de Volta Redonda. 2008. Volta Redonda/RJ.

VOLTA REDONDA. Lei Municipal $\mathbf{n}^{\circ} \mathbf{4 . 8 0 0 / 1 1}$. Cria, no âmbito da Secretaria Municipal de Saúde, o Departamento de Atenção e Vigilância em Saúde. 2011. Volta Redonda/RJ.

VOLTA REDONDA. Secretaria Municipal do Meio Ambiente. Ofício nº 001/2017. Volta Redonda: SMMA, 2017. 